\title{
Inquiry-based approaches to mathematics learning, teaching, and mathematics education research
}

\author{
Kim Beswick ${ }^{1}$
}

Accepted: 15 March 2021 / Published online: 23 March 2021

(c) The Author(s), under exclusive licence to Springer Nature B.V. 2021

Three of the four articles in this issue (Andrews-Larson, Johnson, Peterson, \& Keller; Wright; Florensa, Bosch, \& Gascón) deal explicitly with supporting mathematics teachers to move from teaching approaches characterized as traditional toward approaches based on inquiry. This focus foregrounds concern for pedagogy but in each case teachers' knowledge, conceptualized in different ways, is also a consideration. For Weiland, Orrill, Nagar, Brown, and Burke, the knowledge upon which middle school teachers can draw in their teaching of proportional reasoning and that constitutes robust understanding of that concept is the central focus. Nevertheless, concern for pedagogy, particularly aspects of pedagogical knowledge, is also apparent in their report. As a collection, the articles offer diverse conceptualizations of mathematical knowledge and raise questions about that knowledge, what it means to do mathematics and the broad social purposes of that activity, the intersection of research and teaching, and the relationship between teachers and researchers. All of the studies reported involved small numbers of participants and detailed analyses of qualitative data and hence questions as to the scalability of the approaches suggested also arise.

Andrews-Larson et al. examined how two groups of undergraduate mathematics instructors engaged in pedagogical reasoning as part of a workshop on inquiry-oriented instruction. Each group engaged with a mathematics task in either abstract algebra or linear algebra firstly in the role of doers of mathematics and then as mathematics instructors as they viewed video of students working on the same task. Andrews-Larson et al. found that the more deeply the mathematicians engaged with the mathematics inherent in the task, the greater was their engagement with the evidence of student mathematical reasoning evident in the video. The group that engaged more deeply with the mathematics and student reasoning were more likely to focus on supporting students in their mathematical work and maintaining the students' ownership of the ways in which they represented the mathematics. This was in contrast to the group that engaged less deeply with the mathematics and hence with the evidence of student thinking, that focussed more on describing the representational choices that the students made and on evaluating the students' contributions. Andrews-Larson et al. note subtle differences in the ways in which the facilitators of the two groups oriented the participants to their task and speculate that this may account for the difference in the foci of the activity of the two groups. The authors further venture that

Kim Beswick

k.beswick@unsw.edu.au

1 University of New South Wales, Sydney, Australia 
an initial focus on mathematics rather than on pedagogical issues may be a useful entry point into examining student reasoning for mathematicians because of the greater likelihood that they will share common understandings and beliefs in this regard compared to in relation to matters related to instruction. In addition, they point to the value of using evidence of students' partially formulated understandings rather than completed solutions as a prompt for discussion of students' reasoning.

Andrews-Larson et al. are cognisant of the limitations of their study and of the range of important questions that their findings offer for further research. Although considerable research has been conducted on helping schoolteachers to analyze, respond to, and build upon student thinking, its application in tertiary settings has mainly been to teacher education rather than to undergraduate mathematics teaching (Andrews-Larson et al.). While there is scope to test the applicability of findings from school mathematics to undergraduate mathematics, the reverse should also be considered. To what extent, for example, might the quality of schoolteachers' engagement with the mathematics inherent in tasks support their capacity to engage with student reasoning about those tasks in productive ways? Certainly, for Weiland et al., middle school teachers' own robust understanding of proportional reasoning is fundamental to their ability to teach these ideas as it constitutes the knowledge resources upon which they can draw in their teaching.

Like Andrews-Larson et al., Wright frames the need for change to dominant approaches to mathematics teaching in terms of the negative impacts, both cognitive and affective, of such teaching for many students, but goes beyond this to draw attention to the socio-political implications of traditional mathematics teaching practices in which attainment correlates with students' socioeconomic status, and students deemed less capable experience impoverished curricula and pedagogies. He argues that traditional mathematics education has not recognized its inherently political nature nor sufficiently acknowledged the contextual constraints within which teachers work. Wright reports on the Teaching Mathematics for Social Justice project in which he worked alongside five secondary mathematics teachers using participatory action research to support the teachers to change their practice in line with the aims of the project. He describes how the use of tasks that used mathematics to address questions of justice such as fair trade led to increased student engagement with and enjoyment of mathematics. In addition, he notes shifts in the teachers' discourse around student ability and attainment that included questioning commonplace practices such as setting (grouping according to prior attainment) and recognizing that, rather than being a meritocracy, education can perpetuate inequity. Teachers began to articulate views consistent with Jorgensen's (2016) claim that less advantaged students need to be assisted to develop the skills and attitudes that middle class students bring to their learning and that position them to take full advantage of the opportunities afforded them to learn. Wright acknowledges the role that he played as researcher in bringing an external perspective to the collaboration in a way that is reminiscent of Lerman's (1997) notion of a second voice.

Both Wright and Andrews-Larson et al. implicitly acknowledge precursors to changed teaching practices that mathematics educators have been aware of for decades. Jakubowski and Tobin (1991), for example, recognized that teachers will only do the significant work required to substantially change their classrooms if they are convinced that the effort is warranted, and Nespor (1987) articulated the additional requirement that change requires the availability of a feasible alternative paradigm. Although these conditions are somewhat obvious, the field is still grappling with how they can be achieved. Whereas Andrews-Larson et al. cite evidence that many mathematicians acknowledge the need to reform undergraduate mathematics teaching and many report using alternatives to traditional lectures alone, Wright presents participatory action research as a means of bringing teachers to a 
place of problematizing usual practice, thereby motivating change. The provision of tasks that provided an entree into inquiry-oriented instruction (Andrews et al.) or mathematics for social justice (Wright) went some way toward offering an alternative paradigm for the teachers to adopt. Questions remain, however, in both cases, as to the extent to which the teachers concerned were able to extend the new approaches to their teaching more broadly. In the case of Wright's project, there was encouraging evidence that the tasks used by project teachers were being adopted more widely in their schools but given that the focus of the project was on social justice with mathematics as a powerful tool for investigating issues, concerns about the extent to which such an approach can be applied across the mathematics curriculum arise. It could be that the changes in teachers' thinking about the capabilities of students deemed low attainers, such as Wright observed, is a key motivator of sustained change (Beswick, 2018).

Weiland et al. point to a disparity between the recognized importance of proportional reasoning and the relative lack of research on teachers' knowledge of proportions. Research that does exist tends to focus on deficits in teachers' knowledge (e.g. Lobato, Orrill, Druken, \& Jacobsen, 2011) and the difficulties that it presents for teachers (e.g. Lamon, 2007). Weiland et al. drew from the literature to develop a framework for robust understanding of proportional reasoning and from clinical interviews with 32 practising middle school teachers to identify a set of observable knowledge resources that underpin robust understanding of proportional reasoning. Weiland et al.'s conceptualization of robust understanding as an interconnected system of knowledge resources that can be accessed and used in differing combinations in different contexts draws upon ideas Knowledge in Pieces (e.g. diSessa, Sherin, \& Levin, 2016). They illustrate the potential use of their framework for analyzing teachers' understanding of proportions and for supporting further development of that understanding. They make the point that has some resonance with Andrews-Larson's speculation about the potential value of using mathematics as an entry point into analyzing student thinking, that robust understanding of mathematics is a necessary precondition for being able to respond in the moment to students' ideas. There can be little argument that inquiry-based approaches such as advocated by the Andrews-Larson et al., Wright, and Florensa et al. demand robust understanding, as defined by Weiland et al., of the relevant mathematics.

Florensa et al. address the difficulty that teachers face in making significant changes to their practice in response to curriculum changes or the adoption of unfamiliar pedagogies. They posit Question-Answer (Q-A) maps as a tool to assist teachers to identify and analyze the content they are to teach. Florensa et al.'s concern was also that teachers question taken-for-granted understandings and ways of viewing aspects of content and pedagogy such as the phenomenon of functions being taught in isolation from related mathematical domains. They also challenge the usual research practice of maintaining a separation between researchers' tools and the tools made available to teachers. From their work with 16 secondary mathematics teachers from four Latin American countries in an online course, Florensa et al. found Q-A maps to be a useful in assisting teachers to problematize existing epistemologies in their schools. In emphasising the questionable and dynamic nature of knowledge, the authors consider Q-A maps to be emancipatory and able to broaden the description of the relevant mathematical knowledge beyond that contained in curricula and other documents. Florensa et al. also point to the adaptation of research tools for teachers as an important way to support teachers in this work.

Juxtaposed with Wright's article, one wonders how and to what extent if any research such as that reported by Andrews-Larson et al., Weiland et al., and to a lesser extent perhaps Florensa et al. should or might take account of the socio-political environment in 
which it is conducted and the diverse contexts in which it might be applied. It is also worth remembering that each of these studies, including Wright's, was conducted in particular countries and schools which will have similarities with and differences from other schools, systems, and cultures. Questions are many and concern, for example, the extent to which the knowledge resources that Weiland et al. observed among US middle school teachers might be unique to that context, the ways in which teachers in countries other than the UK in which Wright worked might respond to the idea of social justice through mathematics education, and how might researchers and teachers in both of these countries learn from the Anthropological Theory of the Didactic (Bosch \& Gascón, 2006) that underpinned Florensa et al.'s work. This is a thought-provoking collection of articles that highlight how much more we have to learn.

\section{References}

Beswick, K. (2018). Systems perspectives on mathematics teachers' beliefs: Illustrations from beliefs about students. In E. Bergqvist, M. Österholm, C. Granberg, \& L. Sumpter (Eds.), Proceedings of the 42nd conference of the International Group for the Psychology of Mathematics Education (Vol. 1, pp. 3-18). Umeå, Sweden: PME.

Bosch, M., \& Gascón, J. (2006). Twenty-five years of the didactic transposition. ICMI Bulletin, 58, 51-65.

diSessa, A. A., Sherin, B., \& Levin, M. (2016). Knowledge analysis: An introduction. In A. A. diSessa, M. Levin, \& N. Brown (Eds.), Knowledge and interaction: A synthetic agenda for the learning sciences (pp. 30-71). New York, NY: Routledge.

Jakubowski, E., \& Tobin, K. (1991). Teachers' personal epistemologies and classroom learning environments. In B. J. Fraser \& H. J. Walberg (Eds.), Educational environments: Evaluation, antecedents and consequences (pp. 201-214). Pergamon Press.

Jorgensen, R. (2016). The elephant in the room: Equity, social class, and mathematics. In P. Ernest, B. Sriraman, \& N. Ernest (Eds.), Critical mathematics education: Theory, practice and reality (pp. 127-146). Information Age Publishing.

Lamon, S. (2007). Rational numbers and proportional reasoning: Toward a theoretical framework for research. In F. K. Lester (Ed.), Second handbook of research on mathematics teaching and learning (pp. 629-667). National Council of Teachers of Mathematics.

Lerman, S. (1997). The psychology of mathematics teachers' learning: In search of theory. In E. Pehkonen (Ed.), Proceedings of the 21st Conference of the International Group for the Psychology of Mathematics Education (Vol. 3, pp. 200-207). Lahti, Finland: PME.

Lobato, J., Orrill, C. H., Druken, B., \& Jacobson, E. (2011). Middle school teacher's knowledge of proportional reasoning for teaching. Paper presented as part of J. Lobato (chair), Extending, expanding, and applying the construct of mathematical knowledge or teaching $(M K T)$. New Orleans: Annual Meeting of the American Educational Research Association.

Nespor, J. (1987). The role of beliefs in the practice of teaching. Journal of Curriculum Studies, 19(4), $317-328$.

Publisher's Note Springer Nature remains neutral with regard to jurisdictional claims in published maps and institutional affiliations. 